\title{
DESAIN FASILITAS OLAHRAGA DAN REKREASI DENGAN PENDEKATAN KANONIS DI DURI KEPA, JAKARTA
}

\author{
Angga Ali Putra ${ }^{1)}$, Fermanto Lianto ${ }^{2)}$ \\ 1)Program Studi S1 Arsitektur, Fakultas Teknik, Universitas Tarumanagara, anggaali10166@gmail.com \\ 2)Program Studi S1 Arsitektur, Fakultas Teknik, Universitas Tarumanagara, fermantol@ft.untar.ac.id
}

\begin{abstract}
Abstrak
Masalah kepadatan penduduk sudah menjadi masalah yang cukup lazim di kota besar. Efek yang dapat ditimbulkan dari masalah kependudukan, antara lain munculnya kawasan kumuh, turunya kualitas lingkungan dan dampak terhadap kondisi psikologis berupa stress. Salah satu metode yang dapat memecahkan masalah akibat padatnya penduduk yaitu pembangunan fasilitas pendukung. Suatu perumahan dapat menjadi efektif dan meningkat kualitasnya karena ketersediaan fasilitas pendukung di suatu kelompok hunian. Hal ini dikarenakan fasilitas pendukung dapat memfasilitasi kontak langsung antar individual, dimana beberapa individual dapat melakukan komunikasi. Kemudian adanya fasilitas umum juga dapat memfasilitasi kegiatan rekreasional seperti olahraga yang dapat mengurangi dampak stress. Sehingga dibutuhkan suatu tempat bagi orang yang ingin berkumpul, mengobati stress,kesepian dan keterasingan, tidak hanya dijadikan tempat untuk melarikan diri, tetapi dimana orang akan bersantai, terhibur dan juga mendapatkan ketenangan didalamnya. Fasilitas Olahraga dan Rekreasi di Duri Kepa adalah sebuah proyek yang dibuat agar masyarakat khususnya warga Duri Kepa memiliki tempat untuk bersantai, melepas bosan, dan bebas untuk berekspresi di dalamnya yang diwujudkan dalam aktivitas berolahraga dan berekreasi. Metode desain yang digunakan adalah desain kanonis yaitu perancangan berdasarkan berbagai aspek tertentu seperti sistem proporsi, aspek geometrika objek, tatanan massa, modul yang mengarah kepada keteraturan. Proyek ini berusaha untuk memenuhi kebutuhan fisik maupun sosial masyarakat kelurahannya dengan mudah di jangkau dari first place maupun second place. Project ini akan menjadi tempat yang mewadahi interaksi sosial masyarakat.
\end{abstract}

\section{Kata kunci: Fasilitas Pendukung; Olahraga; Pendekatan Kanonis; Rekreasi; Stress}

\begin{abstract}
The problem of population density has become a fairly common problem in big cities. The effects that can arise from population problems include the appearance of slums, the decline in environmental quality, and the impact on psychological conditions in the form of stress. One method that can solve the problem due to population density is the construction of supporting facilities. Housing can be adequate and improve its quality because of the availability of supporting facilities in a residential group. This is because supporting facilities can facilitate direct contact between individuals, where several individuals can communicate. The existence of public facilities can also facilitate recreational activities such as sports that can reduce the impact of stress. So it takes place for people who want to gather, treats stress, loneliness, and alienation, not only as a place to escape but also to relax, be entertained, and also get peace in it. The Sports and Recreation Facility at Duri Kepa is a project created so that the community, especially the Duri Kepa residents, have a place to relax, unwind, and be free to express themselves as manifested in sports and recreation activities. The design methodology used is canonical design, a design approach based on various aspects such as the geometrical aspects of objects, proportional systems, modules, and mass order, all of which lead to rule as the basis of design. This project seeks to meet the physical and social needs of the village community easily reached from the first place and second place. This project will be a place for community social interaction.
\end{abstract}

\section{Keywords: Canonic Design; Recreation; Sport; Stress; Supporting Facilities}




\section{PENDAHULUAN}

Masalah kepadatan penduduk sudah menjadi masalah yang cukup lazim di kota-kota besar. Efek yang dapat ditimbulkan dari hal ini antara lain munculnya tempat-tempat kumuh kota yang tidak layak huni, tingginya persaingan dalam dunia kerja, stabilitas keamanan yang terganggu dan penurunan kualitas lingkungan. Adapun masalah kepadatan penduduk juga dapat memiliki dampak terhadap kondisi psikologis penduduk seperti stress dan tingkah laku sosial negatif (Whrightsman \& Deaux, 1981).

Salah satu metode yang dapat memecahkan masalah-masalah yang dapat ditimbulkan dari padatnya penduduk yaitu pembangunan fasilitas pendukung. Suatu perumahan dapat menjadi efektif dan meningkat kualitasnya karena ketersediaan fasilitas pendukung di suatu kelompok hunian (Perry, 1985). Hal ini dikarenakan fasilitas pendukung dapat memfasilitasi kontak langsung antar individual, dimana beberapa individual dapat melakukan komunikasi. Hal ini dijelaskan dalam konsep neighborhood unit (Perry, 1985). Kemudian adanya fasilitas umum juga dapat memfasilitasi kegiatan rekreasional seperti olahraga yang dapat mengurangi dampak stress. Agar berfungsi dengan efektif, fasilitas umum harus berada di jangkauan yang dekat dengan hunian masyarakat. Provinsi DKI Jakarta adalah provinsi yang mempunyai kepadatan penduduk yang tinggi khususnya Jakarta Barat. Hal ini dapat dilihat dari jumlah kepadatan penduduk kota Jakarta Barat yaitu 19.516 ribu per km persegi. Angka tersebut lebih tinggi dari kepadatan penduduk yang dimiliki oleh wilayah Jakarta lainnya.

Salah satu daerah di Kota Jakarta Barat yaitu Duri Kepa merupakan daerah yang padat dengan hunian penduduk. Hal tersebut dapat terjadi salah satunya yaitu karena faktor family life cycle yaitu kecenderungan keluarga yang akan tinggal dekat dengan keluarga lainnya (Doling, 1976). Hal ini biasanya dapat terjadi di daerah perumahan lama seperti Duri Kepa. Walaupun daerah Duri Kepa didominasi hunian padat penduduk namun daerah Duri Kepa belum dapat dikatakan memiliki fasilitas yang memadai. Jika dilihat dari persebaran fasilitas, Duri Kepa terbilang dapat memenuhi kebutuhan sehari-hari seperti minimarket,klinik kesehatan, pendidikan, dan tempat makan, walaupun begitu masih ada fasilitas yang belum terpenuhi yaitu ruang terbuka dan sarana olahraga. Maka dari itu dalam proyek ini akan diajukan fasilitas berupa ruang terbuka dan sarana olahraga yang dapat mewadahi aktivitas masyarakat di daerah Duri Kepa.

\section{KAJIAN LITERATUR}

Kajian teoretis ini berbicara tentang hipotesis yang diidentifikasi dengan gagasan konsep proyek yang akan dirancang. Adapun referensi yang menjadi pertimbangan penulis dalam perancangan adalah sebagai berikut:

\section{The Great, Good, Place"}

Tempat ketiga (Third Place) adalah istilah untuk menandakan tempat-tempat publik yang diadakan secara bebas, tetap, formal maupun informal, seperti berkumpul bersama teman atau keluarga. Oldenburg mengklarifikasi bahwa membuat kebun, jalan pusat, bar, bistro, kafe, dan tempat ketiga lainnya adalah inti dari esensialitas sosial jaringan. Memberikan pendirian kepada sistem berbasis suara yang demokratif, ruang-ruang ini memajukan nilai sosial dengan meratakan status pengunjung, membuat kecenderungan untuk afiliasi terbuka, dan menawarkan bantuan mental kepada orang-orang dan jaringan sehingga menjadikan individu semakin humanistik dan peduli satu sama lain. Third Place menurut Oldenberg memiliki 8 karakter yang membentuknya (Oldenberg, 1997), yaitu:
a. On Neutral Ground
b. The Mood is Playful
c. The Regulars
d. The Third Place as Leveler (a leveling place) 


\section{e. A Home Away From Home \\ f. A Low Profile \\ g. Conversation is The Main Activity \\ h. Accessibility and Accommodation}

\section{Sense of Place}

Sense of Place bisa saja diumpamakan sebagai perasaan manusia yang muncul ketika seseorang sedang berada di dalam ruang atau tempat tertentu. Sense of place dapat diterjemahkan seperti hubungan emosional manusia pada suatu tempat. Tempat dapat diartikan sebagai suatu area tertentu yang komponen-komponenya berupa bentuk fisik atau karakter suatu lokasi, persepsi,dan makna yang merupakan hal terpenting dalam menciptakan sebuah sense of place, oleh sebab itu sense of place adalah suatu kepentingan dari ikatan antara tempat tinggal dan manusia yang menempatinya. Hal ini dapat menimbulkan suatu tedensi seseorang dapat menyukai sebuah tempat ketika seseorang merasa aman dan nyaman, tempat tersebut biasanya adalah tempat dimana mereka lahir (Jorgensen \& Stedman, 2001).

Sense of place adalah perpaduan ketidaksadaran dan kesadaran pada sebuah pemahaman, dalam sense of place akan ada sebuah perilaku, pemahaman, serta perasaan (Hockings \& Axford, 2005). Sense of place adalah hal yang melebihi suatu pemikiran atau ide, berusaha untuk menjalankannya pada pemikiran secara struktur dan dapat didefinisikan dengan baik (Kaltenborn \& Williams, 2002). Menurut para ahli, ada beberapa faktor yang memiliki kaitan yang kuat dengan sense of place seperti komunitas, rasa memiliki, karakter tempat, dan kekeluargaan. Hal ini menyimpulkan bahwa dimensi ruang dapat diukur menggunakan hubungan ini. Lima skala yang dapat menandakan sebuah sense of place (Shamai, 1991), yaitu:

a. Skala tujuan dari sebuah wilayah.

b. Skala berada di sebuah tempat yang berarti terdapat sebuah ikatan dari individu terhadap sebuah tempat tertentu.

c. Skala kelangsungan yang berarti terkait dengan menyatunya seseorang terhadap suatu tempat.

d. Skala pengertian dimana perbedaan akan terasa jika berada pada suatu tempat.

e. Skala pengorbanan berarti munculnya sebuah komitmen besar dari individu yang merupakan tingkat tertinggi dalam sense of place.

\section{METODE}

Dalam proses perancangan ini terdapat beberapa metode yang dilakukan perancang untuk mengumpulkan data, yaitu wawancara, survey, dan dokumentasi. Data ini sendiri dibagi menjadi dua yaitu data primer dan data sekunder. Data primer adalah data yang didapat secara langsung dari sumber asli atau tidak memiliki perantara sedangkan data sekunder adalah data yang diperoleh perancang secara tidak langsung yaitu melalui media perantara. Metode desain yang digunakan adalah desain kanonis (Canonic Design) yaitu perancangan berdasarkan berbagai aspek tertentu seperti sistem proporsi, aspek geometrika objek, tatanan massa, modul yang mengarah kepada keteraturan (BroadBent, 1973; ).

\section{DISKUSI DAN HASIL}

Ide dalam rancangan proyek ini timbul akibat permasalahan inti yaitu ketidaktersediaan fasilitas ruang publik dan sarana olahraga di daerah Duri Kepa sehingga perancang ingin membuat desain berupa ruang publik yang dapat dinikmati semua kalangan masyarakat Duri Kepa, bukan hanya untuk aktivitas berolahraga tetapi juga menyediakan ruang interaksi masyarakat yang menekankan pada ruang terbuka hijau. 
Jenis kegiatan menjadi faktor penting untuk menghidupkan area sekitar tapak. Terdapat dua rancangan program pada tapak yaitu program penunjang dan program utama. Program utama didalam tapak ini yaitu berolahraga dengan sifat rekreasional. Terdapat beberapa faktor dominan untuk mewujudkan fasilitas olahraga ideal yang dibutuhkan Duri Kepa seperti kondisi pada fasilitas olahraga dan Jenis fasilitas olahraga yang ada. Jenis fasilitas olahraga menjadi hal penting pada proyek ini artinya dapat menampung banyak jenis kegiatan olahraga sehingga masyarakat Duri Kepa dapat melakukan berbagai macam jenis olahraga dalam satu tempat, selain itu kondisi pada fasilitas olahraga juga menjadi faktor penting karena harapan warga kondisi fasilitas olahraga nantinya harus aman, lengkap, terawat, bersih, hijau, dan nyaman. Faktor penunjang terdapat kegiatan komersil seperti area food court dan retail yang diharapkan menjadi area tujuan pengunjung untuk berkumpul dan bersantai.

Pada proses mendesain massa bangunan, perancang memperhatikan arah utara yang tegak lurus dengan sisi miring bentuk tapak (trapesium) sehingga tercipta ruang segitiga di setiap hook tapak, hal tersebut dimanfaatkan perancang menjadi area masuk ke bangunan (Gambar 1). Dalam mendesain proyek ini perancang memperhatikan unsur permeabilitas dengan memberikan unsur terbuka pada setiap area masuk, sehingga pengunjung merasa bebas untuk mengakses bangunan yang di wujudkan dengan ruang yang lega dan langit-langit tinggi untuk memberikan kesan lapang.
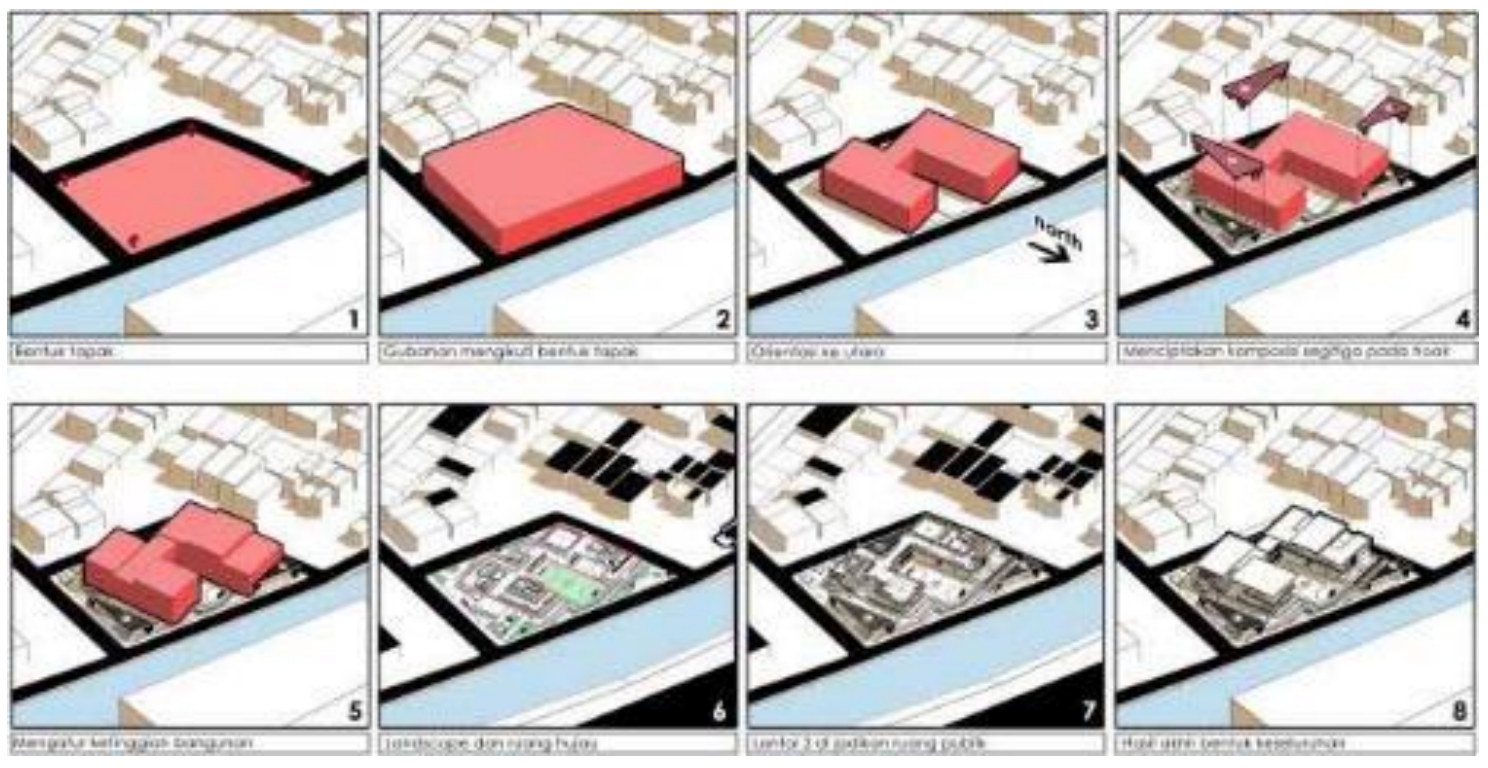

Gambar 1. Proses Gubahan Massa

Sumber: Penulis, 2020

Konsep desain yang dihadirkan pada rancangan ini yaitu menghadirkan unsur vegetasi dengan penerapan vertical garden pada bangunan, selain itu dalam proyek ini perancang juga mencoba menghadirkan unsur terbuka pada bangunan sehingga siapa saja merasa bebas untuk masuk (Gambar 2). 


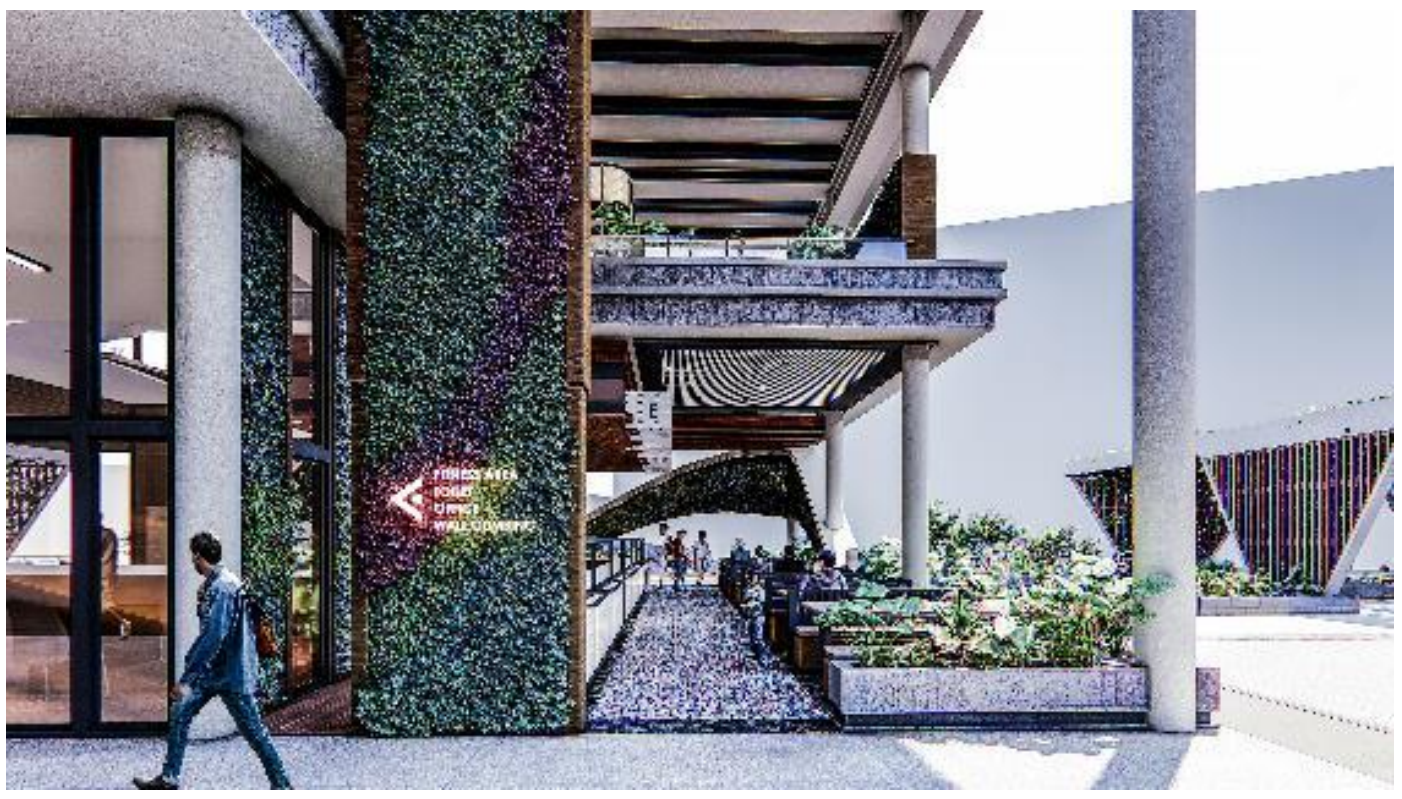

Gambar 2. Penerapan Vertical Garden di Area Entrance

Sumber: Penulis, 2020

Pada area entrance bangunan yaitu terdapat area food court yang langsung dapat dilihat dari jalan sehingga dapat menarik perhatian orang. Area food court diharapakan menjadi area berkumpul dan bersantai serta dapat menjadi area yang nyaman untuk melakukan sebuah pertemuan. Pada area depan juga terdapat amphitheatre yang dapat dipergunakan sebagai area untuk duduk dan berkumpul (Gambar 3).

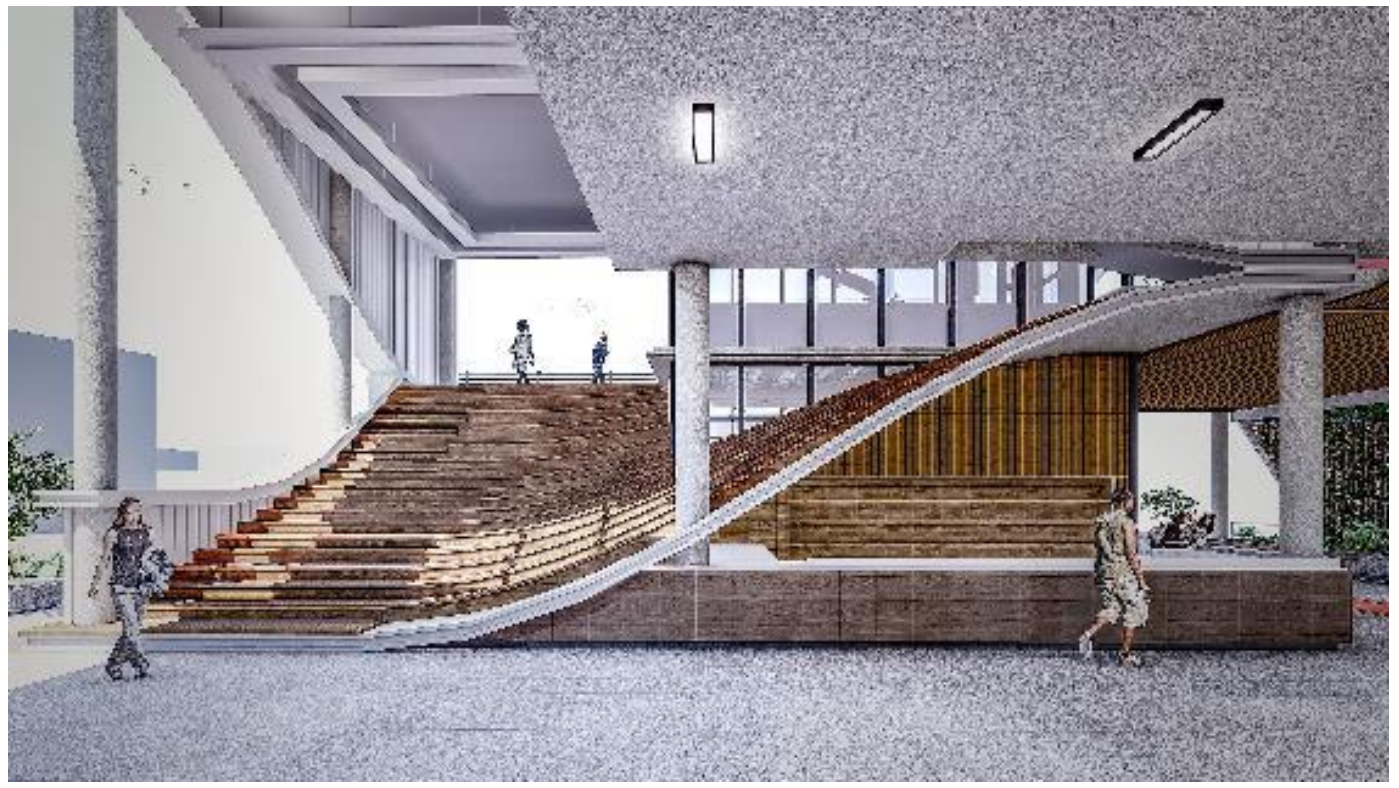

Gambar 3. Rancangan Desain Amphitheatre

Sumber: Penulis, 2020

Penerapan desain amphitheatre dibuat bergelombang untuk memberikan kesan tidak kaku dimana pembuatannya menggunakan beton dengan finishing kayu laminated. Pada bagian bawah amphitheatre dimanfaatkan sebagi ruang informasi dan ruang penitipan barang. Beberapa aktivitas olahraga yang ada pada proyek ini juga dibuat interaktif seperti treadmill tanpa listrik. Penggunaaan material pada alat ini menggunakan besi yang di finishing dengan kayu dan rumput sintesis pada lingkaran untuk berlari (Gambar 4). 


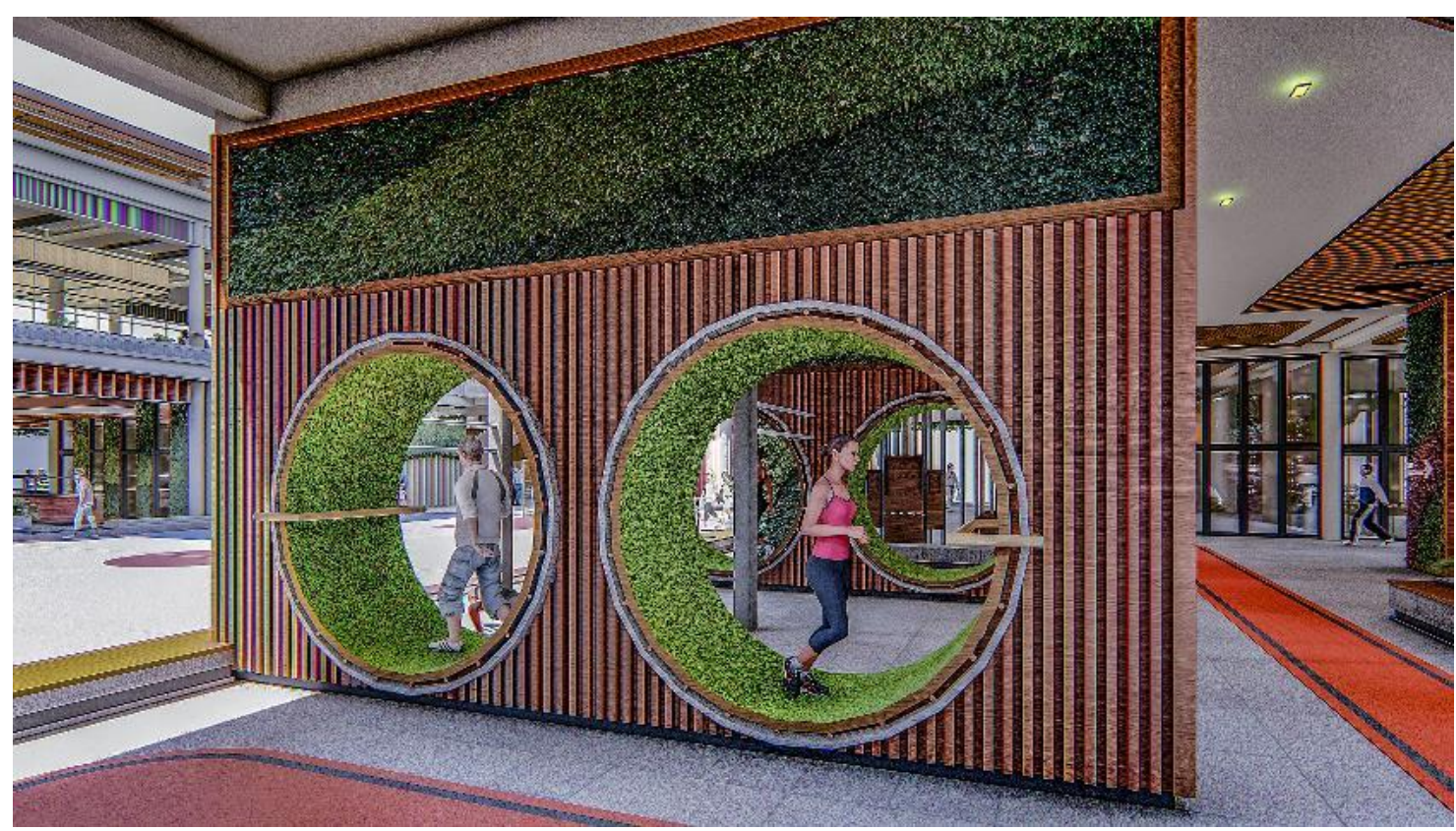

Gambar 4. Penerapan Desain Olahraga Interaktif

Sumber: Penulis, 2020

Selain treadmill ini juga terdapat area pull-up dan jogging track yang berada pada indoor maupun outdoor sehingga memberikan pengalaman ruang yang berbeda ketika orang jogging pada jalur yang telah dibuat. Jalur jogging yang dibuat dibuat kontras dengan warna lantai. Pada area ini juga dibuat seating area yang pengaplikasian kursi dan mejanya dapat dilipat. Hal tersebut dapat menambah space pada ruang jika sewaktu-waktu dibutuhkan (Gambar 5).

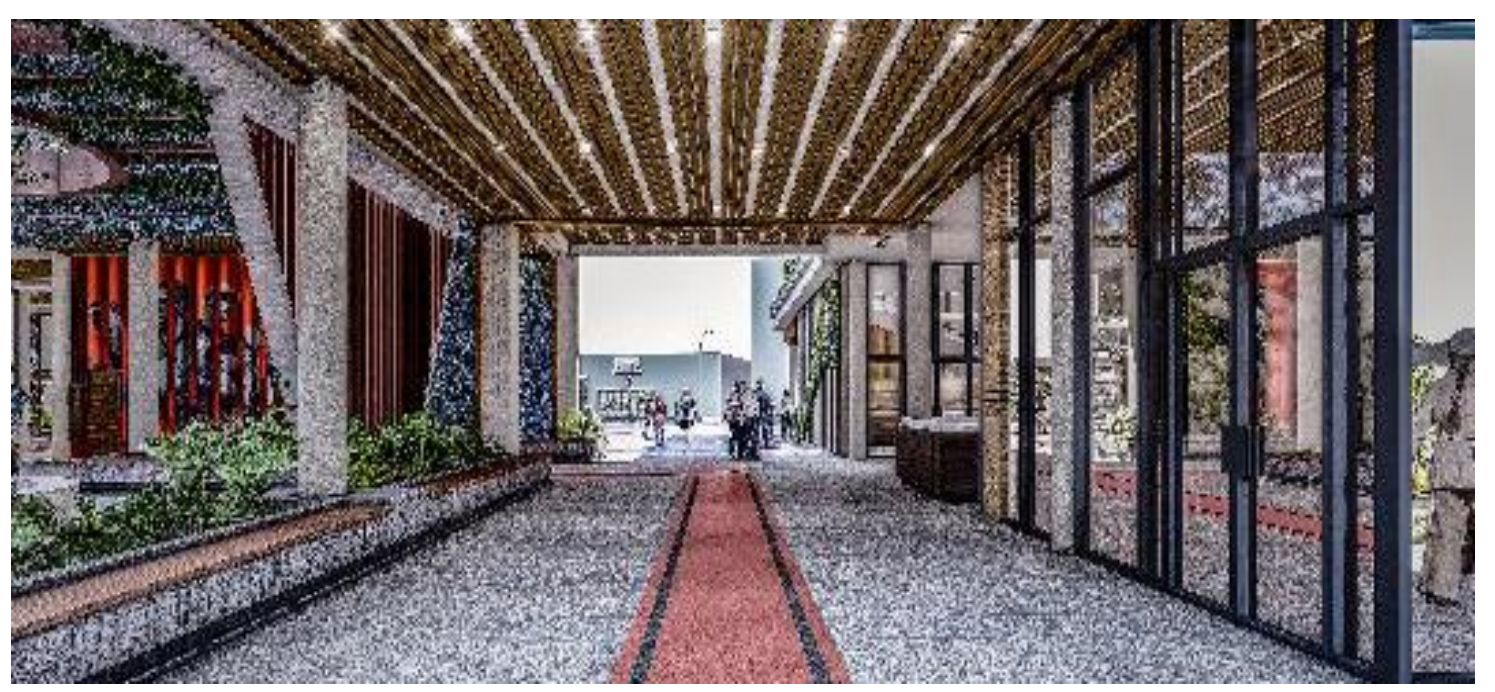

Gambar 5. Penerapan Jogging Track pada Ruang Dalam / Indoor Area Sumber: Penulis, 2020 


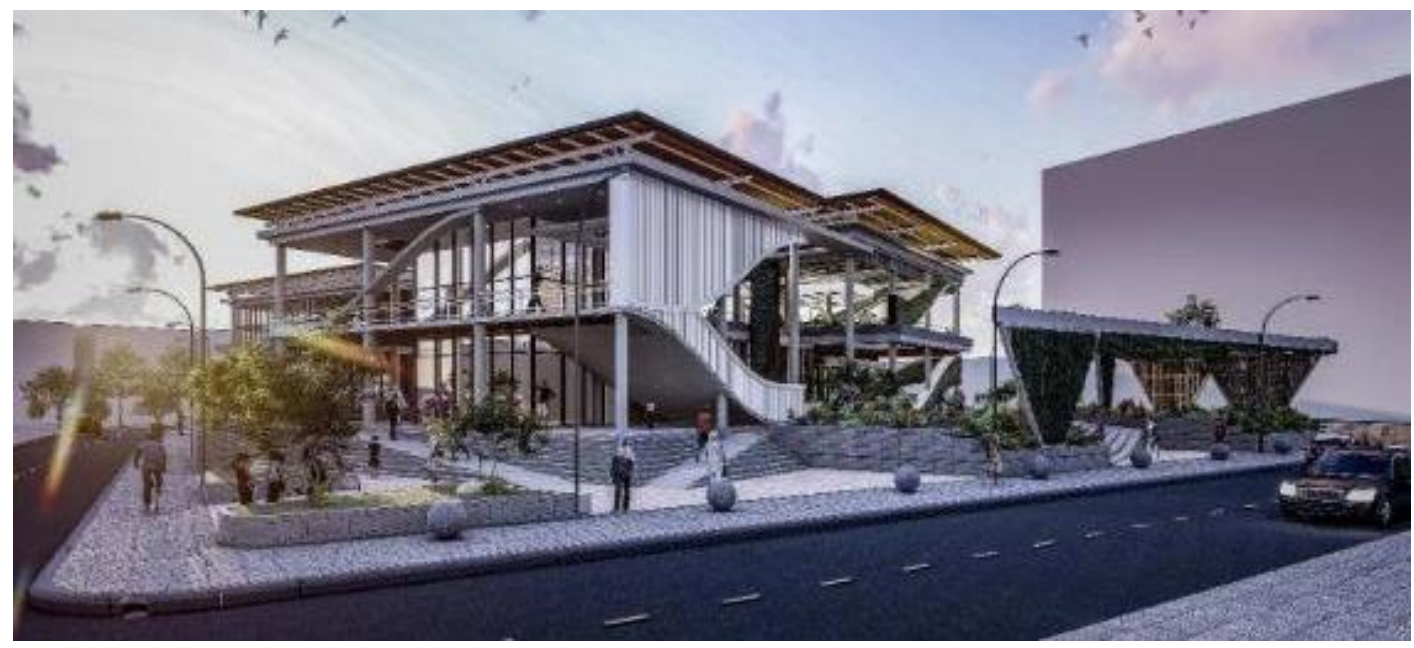

Gambar 6. Gambar Visual Eksterior Bangunan Sumber: Penulis, 2020

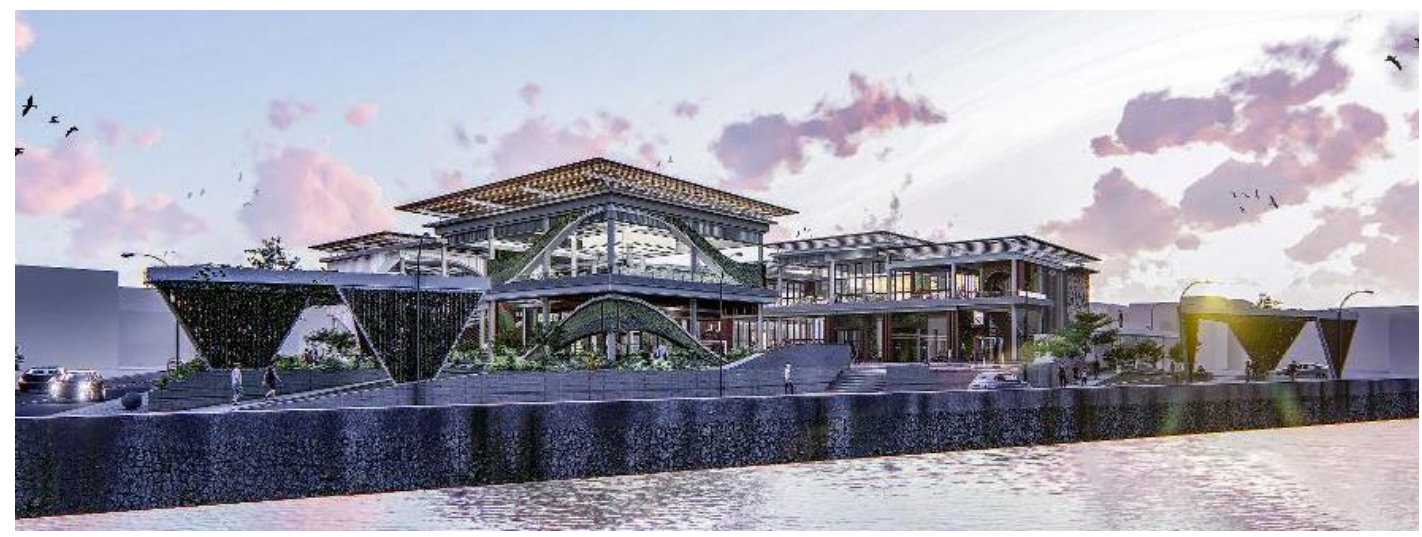

Gambar 7. Gambar Visual Eksterior Bangunan dari Arah Sungai Sumber: Penulis, 2020

\section{KESIMPULAN}

Kebutuhan masyarakat Duri Kepa terhadap ruang terbuka dapat terlihat dari pesebaran fasilitas dan juga kurangnya ruang terbuka di daerah sana. Duri Kepa memiliki jumlah penduduk yang tinggi dibandingkan kelurahan lainya di kecamatan Kebon Jeruk sehingga membutuhkan ruang publik dan fasilitas pendukung agar kualitas kehidupan masyarakatnya dapat efektif dan meningkat. Setelah melihat dan mencari tahu mengenai kebiasaan, aktivitas dan juga karakteristik di daerah sana maka muncul pemikiran untuk membuat sebuah tempat yang dapat mewadahi aktivitas masyarakat Duri Kepa untuk berinteraksi dan berkumpul yaitu fasilitas olahraga dan rekreasi di Duri Kepa. Tempat ini dibuat agar masyarakat khususnya warga Duri Kepa memiliki tempat untuk mereka bersantai, melepas bosan, dan stress serta bebas untuk berekspresi di dalamnya yang diwujudkan dalam aktivitas berolahraga dan berekreasi. Proyek ini berusaha untuk memenuhi kebutuhan fisik maupun sosial masyarakat kelurahannya dengan mudah di jangkau dari first place maupun second place dan menjadi tempat yang mewadahi interaksi sosial masyarakat.

\section{REFERENSI}

BroadBent, G. (1973), Design In Architecture. Architecture and the Human Sciences. London: John Wiley and Sons Inc.

Doling, J. (1976). The Family Life Cycle and Housing Choice. Urban Studies 13(1), 55-58. https://www.jstor.org/stable/43081368?seq=1 
Hockings, M. \& Axford, J. (2005). Sense of place: A tool to assist the meaningful engagement of communities in protected area management. International Conference on Engaging Communities, Brisbane, QLD, Australia, 14-17 August 2005. Brisbane, QLD, Australia: Queensland Department of Main Roads. Retrieved from https://espace.library.uq.edu.au/view/UQ:102844

Jorgensen, B. S. \& Stedman, R. C. (2001). Sense of Place as an attitude: Lakeshore Owners Attitudes Toward Their Properties. Journal of Environmental Psychology 21(3), 233-248. DOI: 10.1006/jevp.2001.0226

Kaltenborn, B.P. \& Williams, D. R. (2002). The meaning of place: attachments to Femundsmarka National Park, Norway, among tourists and locals. Norsk Geogra?sk Tidsskrift-Norwegian Journal of Geography 56, 189-198.

Oldenberg, R. (1999). The Great Good Place: Cafés, Coffee Shops, Bookstores, Bars, Hair Salons, and Other Hangouts at The Heart of A Community. Cambridge: Da Capro Press.

Perry, C. (1929). The neighborhood unit, a scheme of arrangement for the family-life comunity. Monograph 1 in vol.7 of Neighborhood and Community Planning. New York: Commite on Regional Plan of new Yorkand Its Environs.

Shamai, S. (1991). Sense of Place: An Empirical Measurement. Geoforum 22(3), 347-358. DOI: 10.1016/0016-7185(91)90017-K

Whrightsman and Deaux (1981). Social Psychology in the 80's. Monterey. California: Brools. 